pressures would reduce the capacity of a superficial varicose vein, distended to the maximum hydrostatic pressure, by more than $90^{\circ}{ }_{0}$. Surgeon 1 achieved a mean bandage pressure of $30 \mathrm{~mm} \mathrm{Hg}$, which would reduce the capacity of the vein model by only $75^{\circ}$ o if no pads were included. It is still unresolved, however, whether it is more important to consider the volume of the compressed vein at the hydrostatic distending pressure or at mean venous ambulatory pressures, which will be lower if the calf muscle pump is efficient. The hydrostatic pressure is the highest sustained pressure likely to be experienced by the vein, though very high local pressure transients may occur at the junction of an incompetent perforating vein and a varicose vein when the calf muscles contract forcefully. These high pressures may not generally last long enough to reopen a partially sclerosed segment of vein under compression. Venous ambulatory pressures of $52 \mathrm{~mm} \mathrm{Hg}$ have been recorded from superficial foot veins in patients with venous insufficiency. ${ }^{4}$ When the vein model is distended to this lower pressure the same bandage compression of only $30 \mathrm{~mm} \mathrm{Hg}$ would reduce the capacity of the model by $96^{\circ}$.

The optimum bandage pressure for compression sclerotherapy has still to be defined, although our results may suggest an effective range of pressures. In a few experiments pressurevolume curves were recorded from the vein model placed under a National Health lightweight support stocking, which exerted a pressure of $8.5 \mathrm{~mm} \mathrm{Hg}$ around the calf. This pressure reduced the capacity of the model by only $22^{\circ}{ }_{0}$ and is clearly inadequate for sclerotherapy treatment. A bandage pressure greater than $50 \mathrm{~mm} \mathrm{Hg}$, however, is said to be high enough to represent a potential hazard to the arterial inflow to the limb under certain circumstances. ${ }^{5}$ Results from this study suggest that when a narrow foam pad is included over the injection site pressures as high as $50 \mathrm{~mm} \mathrm{Hg}$ are not necessary, assuming that successful fibrous occlusion of the vein can take place if its capacity is reduced by at least $90 \%$ at maximum hydrostatic distending pressures. Although it is not known how empty the injected vein must be during the treatment, more complete emptying of the vein may reduce the incidence of complications such as thrombophlebitis associated with sclerosant injections. For this reason, bandage pressures of more than $30 \mathrm{~mm} \mathrm{Hg}$ are possibly indicated, since below this pressure a significant volume of blood may be present within the vein when it is subjected to high distending pressures.

The considerations discussed in this paper point to the need to measure the pressure applied by limb bandages when assessing the treatment of varicose veins by compression sclerotherapy. Clearly the degree of compression achieved is more variable than many would have believed. Individual surgeons should be aware of the pressures at which they apply compression bandages. The scope of our study did not make it possible to determine whether these bandage pressures are adequately maintained for the whole time during which bandages are worn.

We thank Mr G S Makin and Mr O W Kingdon for their encouragement and advice. This study was supported by a grant from Messrs Elbeo Limited.

\section{References}

${ }^{1}$ Fegan, W G, Proceedings of the Royal Society of Medicine, 1960, 53, 837. 2 Fentem, P H, Goddard, M, and Gooden, B A, British Medical fournal, 1976, 1, 254.

${ }^{3}$ Fentem, P H, Goddard, M, and Gooden, B A, Fournal of Physiology, in press.

4 Somerville, J J F, et al, British fournal of Surgery, 1974, 61, 979.

${ }^{5}$ Ashton, H, British Medical fournal, 1966, 2, 1427.

\title{
Histocompatibility antigens, autoantibodies, and immunoglobulins in alcoholic liver disease
}

\author{
R J BAILEY, N KRASNER, A L W F EDDLESTON, ROGER WILLIAMS, D E H TEE, \\ DEBORAH DONIACH, L A KENNEDY, J R BATCHELOR
}

British Medical fournal, 1976, 2, 727-729

\section{Summary}

Determination of histocompatibility antigens in 63 patients with alcoholic liver disease showed that HLA-B8

Liver Unit, King's College Hospital, London SE5 8RX

R J BAILEY, MD, FRCP(C), research fellow

N KRASNER, MD, MRCP, research fellow

A L W F EDDLESTON, DM, MRCP, senior lecturer in medicine and consultant physician

ROGER WILLIAMS, MD, FRCP, director and consultant physician

Department of Pathology, King's College Hospital, London SE5 8RX D E H TEE, MB, MRCPATH, immunologist

Department of Immunology, Middlesex Hospital, London W1 DEBORAH DONIACH, MD, FRCP, professor of immunology

Tissue Typing Laboratory, Guy's Hospital, London SE1 L A KENNEDY, technician

McIndoe Memorial Research Unit, Queen Victoria Hospital, East Grinstead, Sussex

J R BATCHELOR, MD, director of research was more prevalent in patients with cirrhosis than in controls, but among those with fatty liver and minimal fibrosis the prevalence of this antigen was normal. Another noticeable difference was the absence of HLAA28 in the cirrhotic group. In the total series of 219 patients the prevalence of antinuclear and smooth muscle antibodies was raised; they were especially prevalent in patients with cirrhosis. Raised serum IgA and IgG concentrations were also common (found in $\mathbf{5 0} \%$ and $\mathbf{3 7} \%$ respectively) and were again significantly associated with cirrhosis. In contrast, serum IgM levels, which were raised in $46 \%$ of cases, were not significantly related to the presence of cirrhosis but correlated significantly with the degree of portacaval shunting.

These results support recent evidence suggesting that immune responses may be implicated in alcohol-induced liver damage, particularly in its progression to cirrhosis.

\section{Introduction}

Although the development of cirrhosis in the alcoholic is directly related to the quantity of alcohol and the time taken to consume it, an individual susceptibility also seems to be present. ${ }^{1}$ This 
may be based on genetic predisposition, ${ }^{2}$ and the occasional progression to cirrhosis after alcoholic hepatitis despite abstinence from alcohol, ${ }^{3}$ also suggests that factors other than direct toxicity must play a part. The recent demonstration of lymphocyte sensitisation to liver antigens ${ }^{4}$ and direct cytotoxicity to hepatocytes in patients with alcoholic liver disease ${ }^{5}$ suggests that immune reactions are implicated at some stage in pathogenesis.

Similar immune responses occur in chronic active hepatitis, ${ }^{6}$ ? and in this there is an increased prevalence of the histocompatibility antigen HLA-B8. ${ }^{8}$ We have studied the distribution of histocompatibility antigens in patients with various types of alcoholic liver damage. Serum autoantibodies and immunoglobulins were also measured for further indirect evidence of an immune process and of a relation between the titre of autoantibodies and particular histocompatibility antigens as in active chronic hepatitis. ${ }^{10}$

\section{Patients and methods}

Histocompatibility antigens were determined by a microcytotoxicity technique in 63 patients with alcoholic liver disease. ${ }^{11}$ Fifty-three patients had cirrhosis with or without features of simultaneous alcoholic hepatitis, and 10 had fatty liver with early portal tract fibrosis, alcoholic liver damage being confirmed by liver biopsy in each patient. None of the patients were persistently $\mathrm{HBsAg}$ positive by radioimmunoassay, although the antigen was detected transiently in two patients, one of whom developed acute type $B$ hepatitis. The prevalence of histocompatibility antigens among these patients was compared, by $\chi^{2}$ test with continuity correction, with that in a control group of 95 subjects from the same area of south-east England.

These 63 patients together with a further 156 (219 in all) formed the series in which the prevalence of autoantibodies and immunoglobulin levels were determined. Alcoholic liver disease was histologically confirmed in every case. Antinuclear, smooth muscle, and antimitochondrial antibodies were detected by indirect immunofluorescence. ${ }^{12}$ The ages of these patients ranged from 31 to 74 years (mean age 52 years), and results were compared with those from 260 healthy controls aged from 5 to 86 years (mean 44 years). IgG, IgA, and IgM concentrations were determined by the method of Mancini. ${ }^{13}$ In 77 of the 219 patients an estimate of portosystemic shunting was obtained from liver scintiscans with technetium sulphur colloid by determining the peak count rate over the spleen. ${ }^{1014}$

\section{Results}

Twenty-four ( $45 \%$ ) of the 53 patients with cirrhosis had HLA-B8 compared with $24(25 \%)$ of the 95 controls $(P<0.025)$. In the 10 patients with fatty liver and minimal fibrosis there was no increase in prevalence of HLA-B8 (table I). The first series antigen A28 was completely absent in the cirrhotic group but present in $14(15 \%)$ of the controls $(P<0.001$ by Fisher's exact test). The distribution of $\mathrm{ABO}$ and rhesus blood group antigens was normal in all the groups examined.

Autoantibodies-Antinuclear antibody was present in $13 \%$ of the 219 patients compared with $4.6 \%$ of the controls, a statistically significant difference $(P<0 \cdot 001)$. In most patients titres were $1 / 10$ or $1 / 20$ but were over $1 / 80$ in four. Similarly, smooth muscle antibody was present in $21 \%$ of patients compared with only $1.9 \%$ of controls $(P<0.001)$. Again, although most had low titres $(1 / 10$ and $1 / 20)$, eight patients had smooth muscle antibody titres of $1 / 40$ to $1 / 80$. Antimitochondrial antibody was present in four $(2 \%)$ patients, a prevalence not significantly different from that of the control group.

Immunoglobulins-Increases in serum immunoglobulin concentrations were also common in the 219 patients (raised IgG in $37 \%$, IgA in $58 \%$, and IgM in $46 \%$ ). Increases in two or three of the immunoglobulins were often found in the same patient, although increases in the concentration of a single immunoglobulin were also observed. IgA concentrations alone were raised above normal in $11 \%$ of patients, while solitary increases in IgM and IgG concentrations were found in fewer patients $(6 \%$ and $0.5 \%$ respectively). The index of collateral shunting obtained from the peak count rate over the spleen on the scintiscan showed a significant association with $\operatorname{IgM}$ levels $(r=0 \cdot 4138$; $\mathbf{P}<0.01$ ) but not with IgG or IgA concentrations. When examined in relation to the type of liver disease present, there was a significant association between increased concentrations of IgG and IgA and the presence of cirrhosis (table II). A similar association was found for smooth muscle antibodies but not for antinuclear antibodies.

Unfortunately there were too few patients with autoantibodies who had their histocompatibility antigen phenotypes determined to allow analysis of any association between autoantibody titres and the presence of HLA-B8 or any other histocompatibility antigens.

\section{Discussion}

If immune reactions are important in the pathogenesis of alcoholic liver disease then patients with the most severe damage -that is, cirrhosis-would be expected to have evidence of a more intense immune response, and our results suggest that they do.

In several studies it has been suggested that the increase in immunoglobulin concentrations in alcoholic cirrhosis results from collateral shunting that allows antigens derived from the gut to bypass the liver and stimulate production of antibodies in the spleen. ${ }^{15}$ Our finding of a correlation between the increase in serum IgM and a measure of portosystemic shunting supports

TABLE I-Percentage distribution of histocompatibility antigens, including $H L A-A 28$ and $H L A-B 8$

\begin{tabular}{|c|c|c|c|c|c|c|c|c|c|c|c|c|c|c|c|c|c|c|c|c|c|c|c|c|}
\hline & \multicolumn{10}{|c|}{ First series antigens } & \multicolumn{14}{|c|}{ Second series antigens } \\
\hline & A1 & A2 & A3 & A9 & A10 & A11 & A19 & A28 & A29 & A32 & B5 & B7 & B8 & B12 & B13 & B14 & B27 & WB15 & WB16 & WB17 & WB18 & WB21 & WB22 & WB35 \\
\hline $\begin{array}{l}\text { Controls } \\
\text { Patients with } \\
\text { alcoholic liver } \\
\text { disease and } \\
\text { cirrhosis }\end{array}$ & $\begin{array}{l}32 \\
42\end{array}$ & $\begin{array}{l}51 \\
55\end{array}$ & $\begin{array}{l}31 \\
26\end{array}$ & $\begin{array}{l}15 \\
23\end{array}$ & $\begin{array}{r}9 \\
15\end{array}$ & $\begin{array}{r}21 \\
8\end{array}$ & $\begin{array}{r}18 \\
5\end{array}$ & $\begin{array}{r}15 \\
0\end{array}$ & $\begin{array}{l}7 \\
6\end{array}$ & $\begin{array}{r}5 \\
15\end{array}$ & $\begin{array}{r}15 \\
6\end{array}$ & $\begin{array}{l}20 \\
23\end{array}$ & $\begin{array}{l}25 \\
45\end{array}$ & $\begin{array}{l}28 \\
38\end{array}$ & $\begin{array}{l}4 \\
0\end{array}$ & $\begin{array}{r}6 \\
13\end{array}$ & $\begin{array}{l}11 \\
15\end{array}$ & $\begin{array}{r}8 \\
13\end{array}$ & $\begin{array}{l}4 \\
2\end{array}$ & $\begin{array}{r}12 \\
2\end{array}$ & $\begin{array}{r}12 \\
4\end{array}$ & $\begin{array}{l}3 \\
4\end{array}$ & $\begin{array}{r}11 \\
2\end{array}$ & $\begin{array}{l}17 \\
11\end{array}$ \\
\hline $\begin{array}{l}\text { Patients with } \\
\text { alcholic liver } \\
\text { disease with- } \\
\text { out cirrhosis }\end{array}$ & 20 & 40 & 30 & 40 & 10 & 20 & 10 & 10 & 0 & 10 & 10 & 20 & 10 & 10 & 10 & 10 & 20 & 20 & 0 & 10 & 10 & 10 & 0 & 10 \\
\hline
\end{tabular}

TABLE II-Relation of serum autoantibodies and immunoglobulins to type of alcoholic liver damage. Results are percentages of patients

\begin{tabular}{|c|c|c|c|c|c|c|c|c|}
\hline & \multicolumn{4}{|c|}{ Autoantibodies } & \multicolumn{4}{|c|}{ Immunoglobulins } \\
\hline & $\begin{array}{c}\text { No } \\
\text { tested }\end{array}$ & ANA & SMA & AMA & $\begin{array}{c}\text { No } \\
\text { tested }\end{array}$ & $\begin{array}{c}\mathrm{IgG} \\
>9.6 \mathrm{~g} / \mathrm{l}\end{array}$ & $\begin{array}{c}\mathrm{IgA} \\
>0.425 \mathrm{~g} / 1 \\
\end{array}$ & $\begin{array}{c}\operatorname{IgM} \\
>0.18 \mathrm{~g} / 1\end{array}$ \\
\hline $\begin{array}{l}\text { Patients with fatty change with or } \\
\text { without fibrosis } \\
\text { Patients with cirrhosis }\end{array}$ & $\begin{array}{r}52 \\
167\end{array}$ & $\begin{array}{r}8 \% \\
16 \%\end{array}$ & $\begin{array}{r}8 \% \\
27 \%\end{array}$ & $2 \%$ & $\begin{array}{l}31 \\
88\end{array}$ & $\begin{array}{l}19 \% \\
43 \%\end{array}$ & $\begin{array}{l}29 \% \\
63 \%\end{array}$ & $\begin{array}{l}32 \% \\
51 \%\end{array}$ \\
\hline $\begin{array}{l}\text { Significance of difference between } \\
\text { those with and those without } \\
\text { cirrhosis }\end{array}$ & & NS & $P<0.05$ & NS & & $P<0.05$ & $P<0.01$ & NS \\
\hline
\end{tabular}


this hypothesis, but the lack of a similar correlation for IgG and IgA suggests that other factors may be important, one possibility being a general increase in immune responsiveness.

The prevalence of autoantibodies in the present series belies the generally accepted view that they are rarely, if ever, found in alcoholic cirrhosis. ${ }^{16}$ They were less prevalent in our patients than in those with chronic active hepatitis ${ }^{17}$ but more prevalent than in the controls. Furthermore, although the titres were generally low, similar titres are found in some patients with chronic active hepatitis. ${ }^{17}$

We have suggested that the higher prevalence of HLA-B8 in chronic active hepatitis occurs because this antigen is linked to genes that promote abnormally raised and prolonged antibody responses. ${ }^{10}$ While HLA-B8 is also fairly prevalent $(45 \%)$ in alcoholic cirrhosis, the association is not as great as in HBsAgnegative chronic active hepatitis, in which more than $60 \%$ of the patients have this histocompatibility antigen. ${ }^{18}$ Similarly, the higher prevalence of serum autoantibodies and raised immunoglobulin concentrations is not as striking as in chronic active hepatitis, ${ }^{17}$ and thus immunologically these two groups of patients seem to differ in the intensity of their immune responses. The biological significance of the absence of HLA-A28 is not clear, but this antigen was also not found in any of our patients with $\mathrm{HBsAg}$-negative chronic active hepatitis ${ }^{8}$ nor in those originally reported by MacKay and Morris. ${ }^{9}$

In spite of these genetic similarities there are obvious clinical and histological differences between the two diseases, and there are probably qualitative, as well as quantitative, differences in their immunopathogenesis. Thus, $T$ lymphocytes were recently found to predominate $(91 \%)$ in the portal tract infiltrates in alcoholic liver disease, whereas the proportion in patients with chronic active hepatitis seemed to be much lower. ${ }^{18}$ Possibly these $T$ lymphocytes are reacting to the changes that alcohol may induce in hepatocyte membranes ${ }^{19}$ and are actively implicated in the destruction of these changed liver cells. The intensity of this reaction may determine the rate of progression to cirrhosis, and any factor that may be associated with unusually intense immune responses, such as high immunoglobulin concentrations, autoantibodies, and possibly HLA-B8, would therefore be expected to be particularly common in those who have developed cirrhosis.

We are indebted to the Wellcome Trust for their continued generous support and to Dr Bernard Portmann for the histological assessments. RJB was supported by the Canadian Hepatic Foundation.

\section{References}

1 Rubin, E, and Lieber, C S, Clinics in Gastroenterology, 1975, 4, 247.

2 Maddrey, W C, and Iber, F L, Annals of Internal Medicine, 1964, 61, 667.

3 Galambos, J T, Gastroenterology, 1972, 63, 1026.

4 Mikes, A A, et al, Lancet, 1975, 1, 951.

5 Cochrane, A M G, et al, Gut, 1975, 16, 400.

${ }^{6}$ Miller, J G, et al, Lancet, 1972, 2, 296.

7 Thomson, A D, et al, Nature New Biology, 1974, 252, 271.

${ }^{8}$ Galbraith, R M, et al, British Medical fournal, 1974, 3, 604.

${ }^{9}$ MacKay, I R, and Morris, P J, Lancet, 1972, 2, 793.

10 Galbraith, $\mathrm{R} \mathrm{M}$, et al, Lancet, 1976, 1, 930.

11 Batchelor, J R, in Handbook of Experimental Immunology, ed D M Weir, p 32. Oxford, Blackwell, 1973.

12 Roitt, T M, and Doniach, D, Manual of Autoimmune Serology, Geneva, World Health Organisation, 1969.

${ }^{13}$ Mancini, G, Carbonara, A D, and Heremans, J F, Immunochemistry, 1965, $2,235$.

${ }^{14}$ Eddleston, A L W F, et al, Gut, 1969, 10, 711.

15 Triger, D R, et al, Lancet, 1973, 1, 1494.

${ }^{16}$ Sherlock, S, Clinics in Gastroenterology, 1975, 4, 281.

17 Doniach, D, and Walker, J G, in Progress in Liver Disease, ed H Popper and F Schaffner, p 385. New York, Grune and Stratton, 1972.

${ }^{18}$ Husby, G, et al, fournal of Clinical Investigation, 1975, 56, 1198.

19 Peters, W, et al, Gut, 1975, 16, 826.

\title{
Effect of ethyloestrenol on fibrinolysis in the vessel wall
}

\author{
U HEDNER, I M NILSSON, S ISACSON
}

The spontaneous fibrinolytic activity, local fibrinolytic activity during standardised venous occlusion of the arms, and fibrinolytic activity of the vessel walls increased significantly after treatment with ethyloestrenol $8 \mathrm{mg} /$ day for three months. No further increase occurred after three months, and ethyloestrenol $4 \mathrm{mg} /$ day had no effect. No values rose significantly in the patients with a normal fibrinolytic system. One patient suffered a recurrence within three months of treatment, before the fibrinolytic system became normal. In one patient the fibrinolytic defect reappeared after 10 months in spite of continued treatment. Two of the three women of fertile age developed irregular cycles and intermenstrual bleeding, which disappeared when the treatment was withdrawn. No other side effects were observed.

\section{Introduction}

A defective fibrinolytic defence mechanism (decreased fibrinolytic activator activity in the vein walls or a defective release of fibrinolytic activator from the vein walls, or both) has been found in about $70 \%$ of patients with recurrent deep venous thrombosis (DVT) and no known predisposing condition. ${ }^{1}$ Fearnley $e t \mathrm{al}^{2}$ showed that phenformin $(100 \mathrm{mg} /$ day $)$ combined with ethyloestrenol $(8 \mathrm{mg} /$ day) increased the spontaneous fibrinolytic activity of the blood. The same treatment was later

Coagulation Laboratory, Allmänna Sjukhuset, Malmö, and Department of Surgery, Halmstad, Sweden

U HEDNER, MD, associate professor, coagulation laboratory

I M NILSSON, MD, professor of medicine, coagulation laboratory

$S$ ISACSON, MD, associate professor, department of surgery 